Higgins, G., Khey, D., Dawson-Edwards, B.C., \& Marcum, C.D. (2012). Examining the link between being a victim of bullying and delinquency trajectories among an African American sample. International Criminal Justice Review, 22(2), 110-122. Published by Sage (ISSN: 1556-3855). doi:10.1177/1057567712443965

\title{
Examining the Link Between Being a Victim of Bullying and Delinquency Trajectories Among an African American Sample
}

George E. Higgins, David N. Khey, B. Cherie Dawson-Edwards, and Catherine D. Marcum

\section{ABSTRACT}

The purpose of the present study is to provide an analysis of the link between being a victim of bullying and delinquency trajectories. Using a sample of African Americans ( $n$ 1 14725 ), the results show that three distinct trajectory groups of delinquency are present in the data (low desisting, desisting, and high changing). Further, the results indicate that being a victim of bullying is relevant in distinguishing between these three delinquency groups net other controls (i.e., being male, marijuana use, gang membership, and poor parental support). These results are discussed in theoretical contexts. 
Researchers have consistently shown that there is an overlap between offending and victimization and that the offenders tend to share a substantial number of characteristics (Broidy, Daday, Crandall, Sklar, \& Jost, 2006; Gottfredson, 1981; Jennings, Higgins, Tewksbury, Gover, \& Piquero, 2010; Lauritsen, Sampson, \& Laub, 1991; Mustaine \& Tewksbury, 2000; Schreck, Wright, \& Miller, 2002). Individuals who are offenders are likely to be victims and to be revictimized (Farrell, Tseloni, \& Pease, 2005; Ousey, Wilcox, \& Brummel, 2008), but some have shown that offenders and victims may be different. An important issue within this literature is to determine the types of victimization and potential timing of the victimization and its implications for future delinquent behavior. For instance, one form of victimization that is frequently occurring early in life is bullying. The literature is unclear as to whether bullying victimization is a potential life event that starts individuals on a trajectory of delinquent behavior. Furthermore, researchers should consider the potential for differential impact of bullying across race and ethnic groups. To date, no research has examined if this is the case in the context of African Americans. African Americans are important because of cultural differences in lifestyle that have led to higher per capita rates of both victimization and offending (Gabbidon, 2009; Higgins, 2009; Walker, Spohn, \& Delone, 2004). These lifestyle differences have been noted convincingly through ethnographic study (e.g., Anderson's Code of the Street), yet many researchers have sought to study the victim-offender overlap broadly perhaps including race as an independent variable. Just as the development of "culturally sensitive" programming to address the issues of victimization and offending have come online in the last two decades (particularly targeted for "inner-city" youth), the further development of research into victim-offender overlap for African Americans needs to occur.

The purpose of this study is to contribute to the literature by examining whether African Americans begin to follow delinquent trajectories after being a victim of bullying. To make this contribution, the study begins by presenting a review of theoretical premises that guide research on the victim-offender overlap as well as presenting the literature that examines these premises. Then, the study discusses the importance of bullying victimization and the potential implications from being a victim of bullying. Next, the study sets the stage of the cultural differences of African Americans in the context of the victim-offender overlap. This is followed by the methodology, analysis plan, results, and discussion.

\section{THEORY AND VICTIM-OFFENDER OVERLAP}

The theories to explain the victim-offender overlap come from sociology and criminology. The most popular of these theories is routine activities. Routine activities theory suggests that victimization and offending results from the convergence of a suitable target, motivated offender, and a lack of capable guardianship (Cohen \& Felson, 1979). For the victim-offender overlap, the issue is the opportunity or lifestyle that places the individual at highest risk. In addition, Osgood, Wilson, O'Malley, Bachman, and Johnston (1996) argued that individuals without the oversight of a guardian are likely to produce delinquency. Thus, routine activities theory has been successfully argued to explain victimization and offending. Jennings, Piquero, and Reingle (2011) argued that these two arguments have import for the victim-offender overlap. To date, several researchers have supported this view of the victim-offender overlap by showing that specific characteristics are important for the overlap (i.e., age, sex, and race) as well as other characteristics of the situation (Felson, 1986; Mustaine \& Tewksbury, 2000; Sampson \& Lauritsen, 1990). 
In addition to routine activities theory, peer association (i.e., differential association) has been shown to have importance for the victim-offender overlap. Schreck, Fisher, and Miller (2004) argued that delinquent peer association does not inoculate an individual from delinquency or victimization.

Delinquent peers serve as reinforcers for delinquency, and the reinforcement may be overt or covert. The reinforcement that delinquent peers offer makes them attractive as friends, which may create groups of delinquent peers. To further reinforcement, groups of the peers may commit criminal and delinquent acts placing others in the group at higher risks of victimization. To date, researchers have supported this view (Jennings et al., 2010; Schreck, Stewart, \& Osgood, 2008). Youth gangs provide additional evidence of this type of link between the victim-offender overlap. Those that are parts of gangs are more likely to be delinquent and victims, and not an inoculating agent from delinquency and victimization (Miller \& Decker, 2001; Taylor, Freng, \& Esbensen, 2008; Taylor, Peterson, \& Esbensen, 2007; Thornberry \& Krohn, 2003).

Hirschi's (1969) social bonding theory provides another explanation of the victim-offender overlap. The social bonding theory is one that provides a clear rationale on why individuals should not commit crime. That is, the social bonds (i.e., attachment, commitment, involvement, and belief) provide strong connections with admired others, and out of fear of losing this bond with the admired other, the individual will not perform delinquency. When these bonds are worn or broken, the individual is more likely to perform delinquency. That is, the individual is more likely to engage in a lifestyle that is more conducive for victimization as well. Jennings, Higgins, Tewksbury, Gover, and Piquero (2010) showed that those with lower levels of attachment were more likely to be delinquency and victimized, supporting this premise.

From this discussion, lifestyles (i.e., biological sex and drug use), peer association (i.e., gang membership), and social bonds are important parts of the victim-offender overlap. Unfortunately, these studies are not clear about the role of bullying victimization as a key life event for a delinquent trajectory.

\section{BULLYING VICTIMIZATION}

Bullying is a distinct type of repeated aggression and a systematic abuse of power (Olweus, 1993; Smith \& Sharp, 1994) and is a behavioral problem that can predict future criminality, even across generations (Farrington, 1993). It is also extremely pervasive with about one third of students ages 12 through 18 being affected by various types of bullying in the 2006-2007 school year alone (U.S. Department of Justice, 2011). Bullying at school is an important social problem with important consequences

in the short and long term. These implications range from physical health problems to psychological damage (Ttofi \& Farrington, 2008, 2010). As previously mentioned, bullying also shares many risk factors with offending (e.g., Lo"sel \& Bliesener, 2003). The important issue for this study is an emphasis on the effect of bullying victimization.

To date, only a few studies have examined the connection between being a victim of bullying and subsequent delinquency.1 Bennett (2009) performed a qualitative study of what schools do for children that have been bullied. In her study, she found that one of the deleterious effects of being bullied was delinquency. Biggam and Power (1999) performed a study of individuals that were incarcerated 
and uncovered that many of them were bullying victims. These studies seem to indicate that being a victim of bullying may be an important life event that can be part of or begin a delinquent trajectory. To date, no study has examined this premise directly.

\section{EMPHASIS ON AFRICAN AMERICANS}

This study emphasizes African Americans. Few will argue that, as a group, African Americans are more likely to be involved in lifestyles, delinquent peers, and have weak social bonds that put them into positions that increase the likelihood for delinquency and victimization. Consider that African Americans have some of the highest rates of delinquency and victimization among any other racial or ethnic group (Higgins, 2009); For bullying, victimization rates among African Americans remain high relative to other races/ethnicities when examining the raw data (U.S. Department of Justice, 2011). Upon closer examination, being of Hispanic origin seemed to predict lower bullying victimization generally. Yet, African Americans were among a subset of race/ethnicities, who were statistically more prone to violent bullying victimization (Robers, Zhang, \& Truman, 2011). The problem of bullying seems to become magnified in certain contexts to which African American youths commonly belong. Previous research on an all-African American sample within a lowincome black urban community depicted victimization rates upward to 3 times the national rate of bullying (Fitzpatrick, Dulin, \& Piko, 2007). In fact, this research by Fitzpatrick, Dulin, and Piko (2007) highlights risk factor most predictive of increased odds of bullying perpetration: being hit by one's parents repeatedly (e.g., more than twice).

These issues may be explained as African Americans, largely, reside in a subculture that promotes delinquent activities that result in victimization. Anderson's (1999) "code-of-the-street" purports to explain this proposition. Specifically, the "code-of-the-street" indicates a different culture where violence, aggression, and bullying are often socialized in a manner to increase the individual's social standing in the neighborhood. These tactics are also theorized to reduce one's perception of victimization risk, as individuals that do not adopt the code are viewed as weak and ripe for exploitation. Realized reduction in victimization risk via acting "street," however, is not supported by the literature. Previous research indicates that African American adolescents who adopted street codes across 259 neighborhoods amplified their risk of violent victimization far beyond the typical levels indicative of living in dangerous neighborhoods (Stewart, Schreck, \& Simons, 2006). Thus, acting violently, aggressive, or engaging in bullying may be important since these activities provide ample opportunity for an individual to become a victim. This victimization may come primarily in the form of bullying during school hours. Within this culture, bullying victimization can be viewed as a socializing event that may compel African Americans to commit other delinquent activities that they perceive as normal and begin a delinquent trajectory.

To date, previous studies have not deeply explored the victim-offender overlap while focusing on African American youths. As mentioned previously, many African Americans experience higher risks of being victimized and disproportionately become offenders or continue to offend. The exploration of the etiology of this issue is of extreme importance, particularly as millions of dollars are being spent on evidence-based programming to address these issues among early adolescents. In this context, bullying presents itself as one of the most (if not the most) ubiquitous methods of victimization in early life (U.S. Department of Justice, 2011). How this may shape one's delinquency trajectory is largely unknown. Research into this phenomenon may prove extremely useful for further development of programming to reduce violence among African Americans. 


\section{THE PRESENT STUDY}

The purpose of the present study is to provide an analysis of the relative importance of bullying victimization. Bullying victimization is thought to be an important mechanism for beginning a delinquent trajectory. This study examines this particular connection by exploring the association between bullying and delinquency trajectories while controlling for other theoretical mechanisms that are important for the victim-offender overlap (i.e., lifestyles [being male and marijuana use], gang membership, and social bonds [parental support]). In short, this study expects that bullying victimization will be an important measure that predicts membership in more active delinquency trajectories.

In other words, this study attempts to extend the results from Jennings et al. (2010).

These researchers employ trajectory modeling to observe longitudinal similarities and differences in levels of both delinquency and victimization among a sample of adolescents. This sort of methodology is able to estimate groups with shared levels of delinquency and victimization to determine the risk factors associated with these concepts over time. For example, it can be determined what factors are associated with the estimated group that has the highest rates of delinquency (and, likewise, the highest rates of victimization). Estimating groups of similarly situated individuals becomes extremely helpful when trying to understand a typology of individual that may be most prone to life problems. Upon analyses, Jennings et al. determined that high levels of delinquency and victimization were predicted by the same covariates: inflated levels of low self-control, lack of school commitment, little to no parental monitoring, and being male. Respondents reporting higher levels of self-control, school commitment, and parental monitoring typically were statistically assigned to groups that show better outcomes over time. This study extends this previous research by examining bullying in the same framework.

\section{METHOD}

\section{Sample and Procedures}

The data for this study came from the National Longitudinal Survey of the Youth (NLSY97), a panel survey that began with 8,984 youth that were born between 1980 and 1984.2 The NLSY97 consisted of a representative sample of youth from the U.S. population who were aged 12 to 16 in 1996. This was coupled with a supplemental sample of 2,236 African American and Hispanic adolescents representative of the U.S. population of African American and Hispanics at within the same age. The data from these adolescents came from interviews. The survey was originally designed to capture the longitudinal factors that influence youths' transition from school to workplace. The NLSY captures a number of demographic and lifestyle measures; this study focuses on two relevant factors, perceptions of parental support and self-reported delinquency. The survey also includes a supplemental sample of Hispanic and African American youth.

To arrive at the data for the present study, we used a number of criteria. First, the data for the present study came from four rounds of the survey, 1997-2000, and they are exclusively African American. Second, these individuals were between 13 and 16 years old during the 1997-2000 period. This period of life is important because it provides an opportunity for the respondents to follow the age-crime curve, and it provides the respondents an opportunity to still be directly influenced 
by their previous bullying victimization. Thus, we believe that our data allow us to examine the intersection between bullying victimization and trajectories of delinquency. Given that this study employs a longitudinal methodology, missing data are a reality (Brame \& Piquero, 2003). The missing data for delinquency was low-3\%. From this set of procedures, we used a sample of 725 African Americans. Of these 725 African Americans, 59.2\% were female and $40.8 \%$ were male.

\section{Measures}

Delinquency. The delinquency measure that we used was an additive measure of 5 items. The 5 items were "Have you [ever] 3 purposely destroyed property [in (during the current year)]?" "Have you [ever] stolen anything under 50 dollars [during the current year]?" "Have you [ever] stolen anything over 50 dollars [during the current year]?" "Have you [ever] committed a property delinquency [during the current year]?" and "Have you [ever] attacked to hurt someone or fight with them [during the current year]?" The respondents indicated whether they had or had not (1) yes or (0) no. The scores ranged from 0 to 5 with higher scores indicating that they committed more criminal activity. The internal consistency of the items for each of the years was acceptable between 0.65 and 0.80 .

Independent measures. Several independent measures were used in this study. First, we included a measure of gang membership (i.e., have you ever belonged to a gang). The measure of gang membership was a dichotomous measure 0 for no and 1 for yes. Second, we included a measure of biological sex that was dichotomous 0 for female and 1 for male. Third, we included a measure of whether the individual used marijuana in their lifetime that was dichotomous 0 for no and 1 for yes. Fourth, we included a single-item measure of supportive parenting from MacCoby and Martin (1983). The item that was used in this study was: "when you think about how s/he acts toward you, in general, would you say that she or he is (1) very supportive, (2) somewhat supportive, or (3) not very supportive?" Fifth, a measure of bullying victimization was used to determine if it would be important in starting the delinquency trajectories. In this study, the measure that was used was: Before you turned 12 , were you ever the victim of repeated bullying? 4 The answer choices were dichotomous 0 for no and 1 for yes.

\section{Analysis Plan}

The analysis plan takes place in a series of steps. The first step of the analysis is a presentation of the descriptive statistics and bivariate statistics. The descriptive statistics analysis provides an indication of the general trends that are taking place in the longitudinal data for delinquency, and they provide distribution information for the other independent measures. The bivariate correlations provide some indication of whether test-retest reliability is present among the delinquency measures. In addition, the bivariate correlations provide some indication of the link between the independent measures and the delinquency measures.

The second step is a presentation of the trajectory analysis. The trajectory analysis is produced using SAS Proc Traj. Used in many studies in criminology and psychology (Piquero, 2008), the trajectory methodology is properly suited for identifying distinct trajectories or groups of individuals who follow distinct pathways of a particular behavioral outcome. In this study, the trajectory method 
followed a quadratic form using the Censored Normal (CNORM) option for delinquency from Proc Traj. Two pieces of information were used to determine the optimal form and number of groups:

Bayesian Information Criterion (BIC) and posterior probabilities. Nagin (2005) argued that the maximized $\mathrm{BIC}$ and posterior probabilities that were 0.70 were enough information to suggest that the optimal form and number of groups have been found.

The third step is a presentation of the multinomial logistic regression analysis. This analysis is designed to determine whether being a victim of repeated bullying before age 12 predicts membership in more active delinquency trajectories while controlling for other relevant measures previously found commonly associated with delinquency trajectories (see Jennings et al., 2010).

\section{RESULTS}

\section{Step 1}

The first step provides a descriptive analysis and bivariate correlations of the measures for this study. The descriptive statistics show that delinquency is declining from ages 13 to 16 . Sixtyeight percent of the sample had some gang affiliation in the past year. Fifty percent of the sample were males. Five percent of the sample had used marijuana in their lifetime. Parenting was rated as very supportive. Twenty (20) percent of the sample had been bullied repeatedly before age 12 . Table 1 shows that the bivariate correlations show ample test-retest reliability is present among the delinquency measures ( $r=.26$ to .47$)$. The independent measures have links with the measures of delinquency across the four years of delinquency. Notable exceptions are supportive parenting and delinquency at age 14 and gang membership and delinquency at age 16 . In addition, the correlations do not show large correlations among the independent measures. This means that multicollinearity among the independent measures is not likely to be present. This is particularly important because bullying victimization generally occurs from peers, but this is not highly correlated with gang membership.

\section{Step 2}

Figure 1 presents the trajectory analysis of delinquency. The BIC and satisfactory posterior probabilities (i.e., >.70) indicated that a three group model best represented these data. Trajectory group G1 follows a low stable path of delinquency, trajectory group G2 follows a desisting path of delinquency, and trajectory group $\mathrm{G} 3$ follows a high but changing path. These results are consistent with Piquero's (2008) results that SPGM usually extracts 3-5 groups of delinquency. 
Table I. Descriptive Statistics and Bivariate Correlations

\begin{tabular}{lccccccccc}
\hline Measure & 1 & 2 & 3 & 4 & 5 & 6 & 7 & 8 & 9 \\
\hline I. Del (13) & 1.00 & & & & & & & & \\
2. Del (14) & $0.30^{*}$ & 1.00 & & & & & & \\
3. Del (15) & $0.31^{*}$ & $0.31^{*}$ & 1.00 & & & & & & \\
4. Del (16) & $0.28^{*}$ & $0.26^{*}$ & $0.47^{*}$ & 1.00 & & & & & \\
5. Gang member & $0.16^{*}$ & $0.09^{*}$ & $0.11^{*}$ & 0.05 & 1.00 & & & & \\
6. Male & $0.18^{*}$ & $0.15^{*}$ & $0.15^{*}$ & $0.08^{*}$ & $0.13^{*}$ & 1.00 & & & \\
7. Marijuana use & $0.32^{*}$ & $0.17^{*}$ & $0.08^{*}$ & $0.14^{*}$ & $0.10^{*}$ & $0.11^{*}$ & 1.00 & & \\
8. Supportive parenting & $0.16^{*}$ & 0.05 & $0.17^{*}$ & $0.11^{*}$ & $0.12^{*}$ & 0.06 & -0.07 & 1.00 & \\
9. Bullying victim & $0.16^{*}$ & $0.15^{*}$ & $0.10^{*}$ & $0.14^{*}$ & 0.07 & $0.10^{*}$ & 0.03 & $0.12^{*}$ & 1.00 \\
M & 0.84 & 0.51 & 0.46 & 0.32 & 0.68 & 0.50 & 0.05 & 1.28 & 0.20 \\
SD & 1.11 & 0.92 & 0.96 & 0.77 & 1.07 & - & - & 0.50 & - \\
\hline
\end{tabular}

$*_{p}<.05$.

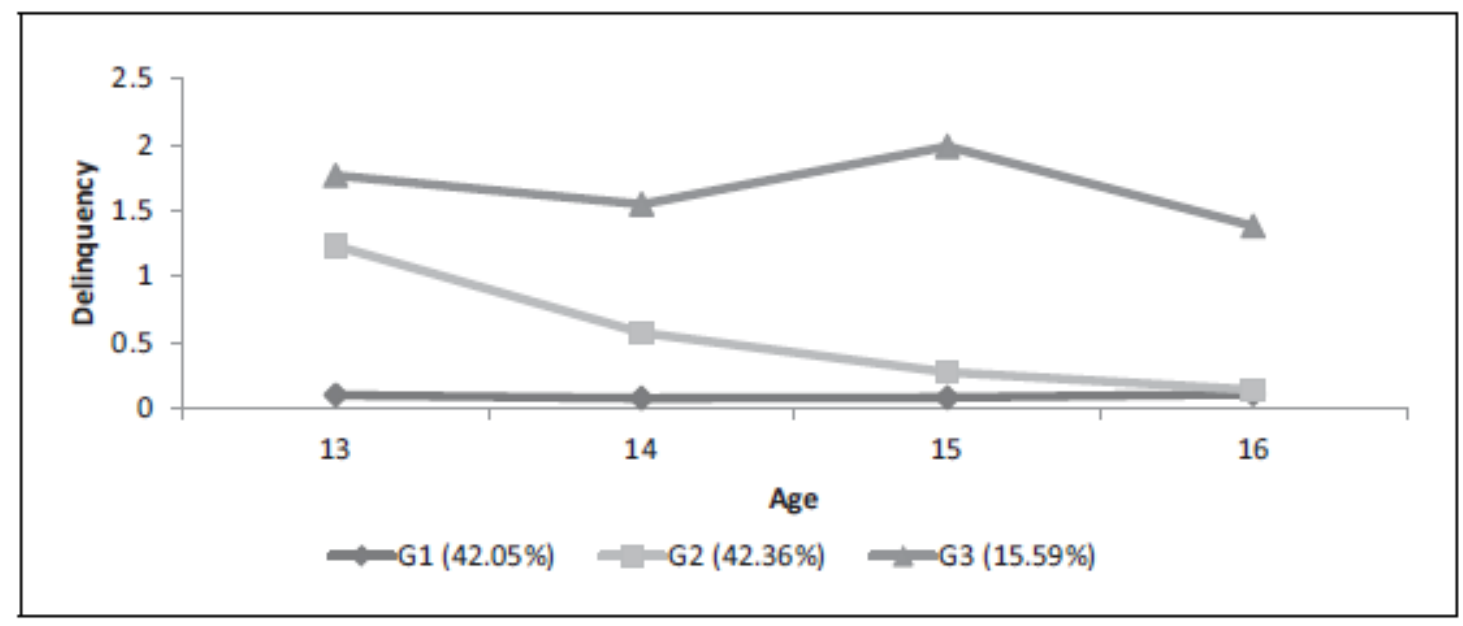

Figure I. Trajectories of delinquency from 13 to 16.

\section{Step 3}

Table 2 presents the results of the multinomial logistic regression analysis. Several independent measures that distinguish between group 1 of delinquency and group 2 of delinquency are gang membership, $\operatorname{Exp}(b)=1.17$; male, $\operatorname{Exp}(b)=1.46$; marijuana use, $\operatorname{Exp}(b)=4.12$; supportive parenting, $\operatorname{Exp}(b)=1.56$. These measures are consistent with their respective literatures that suggest that they are covariates with delinquency and delinquency trajectories. Important for the present study, the results indicate that bullying victimization is important for violence trajectories, $\operatorname{Exp}(b)=2.17$. This means that those that have been the victims of repeated bullying are 2.17 times more likely to follow a delinquency trajectory than those that are not bullied. This is important because the effect of victimization of bullying remains while controlling for the other covariates. 
Table 2 presents the results of the covariates, distinguishing the difference between delinquency group 1 and delinquency group 3. Similar to the results for group 2, the results indicate that several of the independent measures distinguish between delinquency groups 1 and 3. Gang members were 1.28 times more likely to follow delinquency group 3 trajectory rather than delinquency group 1 trajectory.

Table 2. Multinomial Logistic Regression Analysis of Delinquency Trajectory Groups

\begin{tabular}{|c|c|c|c|c|c|c|}
\hline \multirow[b]{2}{*}{ Measure } & \multicolumn{3}{|c|}{ G1 vs. G2 } & \multicolumn{3}{|c|}{ GI vs. G3 } \\
\hline & $b$ & SE & $\operatorname{Exp}(b)$ & $b$ & SE & $\operatorname{Exp}(b)$ \\
\hline Gang membership & $0.16^{*}$ & 0.08 & 1.17 & 0.21 & 0.11 & 1.24 \\
\hline Male & $0.38^{*}$ & 0.17 & 1.46 & $1.15^{* * *}$ & 0.27 & 3.17 \\
\hline Marijuana use & $1.42 *$ & 0.57 & 4.12 & $1.94 *$ & 0.61 & 6.97 \\
\hline Supportive parenting & $0.45^{*}$ & 0.18 & 1.56 & $0.63 *$ & 0.25 & 1.88 \\
\hline Bullying victimization & $0.78^{k 0 *}$ & 0.23 & 2.17 & $1.37^{* 0 * *}$ & 0.29 & 3.95 \\
\hline \multicolumn{7}{|l|}{ Model fit statistics: } \\
\hline Chi-square & $86.52^{* * *}$ & & & & & \\
\hline-2 Log likelihood & 284.83 & & & & & \\
\hline Cox and Snell $r^{2}$ & 0.12 & & & & & \\
\hline Nagelkerke $r^{2}$ & 0.14 & & & & & \\
\hline McFadden $r^{2}$ & 0.06 & & & & & \\
\hline
\end{tabular}

$*_{p} * 0.00 . * p<.05$

Males were 3.17 times more likely to follow delinquency group trajectory 3 rather than delinquency group 1 trajectory. Marijuana users were 6.97 times more likely to follow delinquency group trajectory 3 rather than delinquency group 1 trajectory. Those that had parents that were less supportive were 1.88 times more likely to follow delinquency trajectory group 3 rather than delinquency trajectory group 1 . While these independent measures serve as important covariates and control measures, bullying victimization is found to be a robust and independent indicator of following a delinquency trajectory: The victimization from repeated bullying increases the likelihood of following delinquency group 3 trajectory rather than delinquency group 1 trajectory by a factor of 3.95 times. Thus, bullying victimization is an important predictor in its own right.

The model diagnostics indicate that the model properly fits the data. The chi-square statistic tests whether one of the independent measures regression coefficient (b) is not equal to zero, or that it has a significant effect. The results show that this is indeed the case. The -2 log likelihood is an indication that the model that contains the independent measure is better than a model that does not control for any independent measures. In this study, this is the case. 5 Three psuedo $r 2$ values were presented in the model fit diagnostics. These psuedo $\mathrm{r} 2 \mathrm{~s}$ are not able to be interpreted as typical ordinary least squares $r 2$ values. The Cox and Snell $r 2$ shows whether the models converged to predict the outcome (Long, 1997), our value of .12 indicates that our model did converge. Long (1997) indicated that Cox and Snell does not allow for a 1 to occur, so it is advisable to examine other forms of psuedo r2. Nagelkerke's $r 2$ brings Cox and Snell's version of $r 2$ within the bounds of 0 and 1 (Long, 1997). The Nagelkerke's $r 2$ of .14 indicates that proper convergence has occurred. The McFadden's $r 2$ examines the likelihood that the model without the independent measures is better than the model 
with the independent measures and smaller McFadden's $r 2$ are better (Long, 1997). In this model, McFadden's $r 2$ is .06 suggesting proper fit. The model diagnostics indicate that the model is satisfactory for these data.

\section{DISCUSSION}

The literature on the victim-offender overlap shows that offenders and victims have similar risk factors (Broidy et al., 2006; Gottfredson, 1981; Lauritsen \& Laub, 2007), with some studies suggesting that these individuals are one in the same (Jennings et al., 2010). However, an important area has not received a substantial amount of research attention: This study sought to extend the results from Jennings et al. (2010) by examining whether being a victim of bullying was a specific measure that preceded delinquent trajectories. Furthermore, this study focused its analysis on African American youths, a group that disproportionately experiences higher levels of victimization and offending across the United States. In particular, this study sought to understand whether bullying victimization was part of the Code-of-the-Streets that begins delinquent trajectories for African Americans. Several important results emanate from this study.

First, the results of the study show that three distinct trajectory groups for delinquency are present in these data. The first group (G1) followed a low and stable path of delinquency. The second group (G2) followed a desisting trajectory. The third group (G3) followed a high and changing path of delinquency. These results are consistent with a growing body of research on the heterogeneity of delinquency. In a review of the literature using Semi-Parametric Group-Based Mixture modeling, Piquero (2008) showed that researchers consistently extracted between 3 and 5 groups of delinquency. From a theoretical perspective, while some may argue that heterogeneity is not present in delinquency over time (Sampson \& Laub, 1993), these results support several developmental criminologists' views that heterogeneity will be present in delinquency (see Moffitt, 1993 for reviews). These results are also consistent with the literature that suggests that African Americans have delinquent trajectories.

Second, the results show that being a victim of repeated bullying is an important measure associated with a trajectory of delinquent activity. In this study, bullying victimization distinguished between the two highest trajectory groups of delinquency (G2 and G3) and the lowest trajectory group (G1). Bullying victimization may be a factor that desensitizes individuals from delinquent activity. That is, bullying victimization may be an activity that shows individuals that "street credibility" may be earned through the delinquency among African American boys in particular. This research validates the findings of Stewart, Schreck, and Simons (2006) in that it replicates the association between victimization and delinquency among African American adolescents that adopt the code of the street; it also extends this research by empirically tying bullying victimization to subsequent delinquency for most respondents in the study. It should be noted that $20 \%$ of the African American youths reported they had been repeatedly been bullied before the age of 12 while only $5 \%$ of respondents had engaged in any delinquent behaviors. This suggests that bullying may be an important socializing event for young African Americans, which sets them on a course of "toughening up" by adopting the code of the street to prevent future victimization. Ironically, these events may expose vulnerable youths to elevated levels of subsequent victimization, despite their attempts of stopping or reducing problems. African American adolescents seem to heighten their exposure to victimization by directly confronting potentially violent situations. For example, the Robers, Zhang, and Truman (2011) reported that African American and Hispanic students are more prone to report 
having a gang presence in their schools and live with the fear of attack or harm, and African Americans, in particular, are more likely to face violent victimization relative to students of other races/ ethnicities (along with Hispanics). The data presented here suggest that such perceptions may result with juveniles "toughening up" resulting in flourishing deviance and delinquency.

An important issue here is that bullying victimization remained robust net the significance of the other theoretical measures. To clarify the other theoretical measures, the lifestyles (i.e., being male and marijuana use), gang membership, and poor parental support were important in distinguishing the two higher delinquency groups (G2 and G3) from the lowest delinquency trajectory group (G1). These distinguishing links give credence to the view that the "code-of-the-streets" may be relevant in understanding how bullying victimization may lead to a delinquency trajectory. As a whole, the measures in this study seem to outline a series of lifestyle choices that African Americans make that leads to delinquent trajectories. Anderson (1999) argued individuals aspiring for status will perform delinquent acts. Those that are performing delinquent acts are leaving themselves vulnerable for victimization.

The results of this study show that bullying victimization, whether the result of delinquency or not, is robust against the other mechanisms of other theoretical premises. This is consistent with perspective that African American youth have considerable higher rates of violent victimization and general exposure to violence that coincides with being bullied or bullying (Fitzpatrick et al., 2007; Hazier, Hoover, \& Olliver, 1991).

These results contribute to the victim-offender overlap literature, but they must be kept and consumed within their limits. First, being a victim of bullying was not specific to whether it was in school or elsewhere. This should be inconsequential, given that being a victim of bullying provides physical and psychological damage no matter where the behavior occurred. However, these findings cannot refute the potential of finding differences in outcomes depending on the social climate of the school; if, for example, a school is able to resist the tolerance of street codes on its premises, the temptation for students to fight back or "toughen up" may be reduced. This should not be the case in the vast majority of circumstances, as the culture of surrounding neighborhoods tends to permeate into the schools. Further research should be employed to examine this potential protective factor. One policy implication may be to toughen up the schools' resistance to the code of the street instead of toughening up our youths, and this subsequent research may begin to explore this potential. Second, the trajectories of being a victim of bullying were not possible in these data. The dichotomization of the being a victim of bullying measure does not allow for this to take place. Furthermore, this study only examines a sample of adolescent African American youth by employing self-reported measures of delinquency. Future research should explore the potential of the code of the street to be adopted by other vulnerable youths as well as look at other ways to examine/validate levels of victimization and delinquency. Third, this study does not have the capacity to verify bullying victimization of delinquency; however, it presents strong evidence that suggests that this may be the case. Additional evaluation of the temporal ordering is warranted.

Despite the limits of this study, the results indicate that being a victim of bullying is an important measure for the determination of a delinquent trajectory. Given that the results come from an African American sample, the results suggest that this occurs as part of a subculture within the African American community. Longitudinal measures of being a victim of bullying and more precise measures of being a victim of bullying will help in understanding this better. For now, the results here show that being a victim of bullying is important in delinquent trajectories. Following the logic of 
these results suggests that the application of evidence-based bullying prevention programs such as Al's Pals and Building Assets-Reducing Risks may prove effective in reducing delinquency as well as victimization. African American-specific programs that target bullying and antisocial behavior may prove effective in reducing the pervasiveness of the code of the street.

\section{DECLARATION OF CONFLICTING INTERESTS}

The authors declared no potential conflicts of interest with respect to the research, authorship, and/or publication of this article.

\section{FUNDING}

The authors received no financial support for the research, authorship, and/or publication of this article.

\section{NOTES}

1. Many other studies examine the connection between being a bully and delinquency. Because the focus of this study is the bullying victimization, the studies that examine the connection between being a bully and delinquency were not presented.

2. The NLSY97 survey was typically carried out between February and August 1997. The data were actually collected between November and April of the following years. This may allow for some overlap of individuals in the data. We monitored this process and found that seven individuals in our data appeared more than once. So to not bias the data, we removed these seven individuals. $t$ Tests show that the removal of these individuals did not result in substantively different results. The results of the $t$ tests are available from the first author on request.

3. The first wave questionnaire included these questions regarding delinquency, but asked respondents if they have ever engaged in these behaviors. We included these responses in our scoring noting only $5 \%$ of the sample engaged in these behaviors at Wave 1.

4. To ensure that this took place at least during the age of 12 , the date of birth was used to create the sample at age 12 . This step was taken to ensure proper temporal ordering, given that the delinquency trajectories were developed at age 13.

5. In other words, this occurs when comparing a null model-no independent measures-against a full model-containing independent measures. The results of the null model may be obtained from the first author on request. 


\section{REFERENCES}

Anderson, E. (1999). Code of the street: Decency, violence, and the moral life of the inner city. New York, NY: W. W. Norton.

Bennett, L. J. (2009). What schools do to/for kids who have been bullied: A qualitative study. In B. Slater Stern (Ed.), Curriculum and teaching dialogue (Vol 11[1-2]): Festschrift in honor of O. L. Davis, Jr (pp. 275-292). Charlotte, NC: Information Age Publishing.

Biggam, P. H., \& Power, K. G. (1999). Social problem-solving skills and psychological distress among incarcerated young offenders: The issue of bullying and victimization. Cognitive Therapy and Research, 23, 307-326.

Brame, R., \& Piquero, A. R. (2003). The role of sample attrition in studying the longitudinal relationship between age and crime. Journal of Quantitative Criminology, 19, 107-128.

Broidy, L. M., Daday, J. K., Crandall, C. S., Sklar, D. P., \& Jost, P. F. (2006). Exploring demographic, structural, and behavioral overlap among homicide offenders and victims. Homicide Studies, 10, 155180.

Cohen, L. E., \& Felson, M. (1979). Social change and crime rate trends: A routine activity approach. American Sociological Review, 44, 588-608.

Department of Justice. Office of Justice Programs. Bureau of Justice Statistics. (10/12/1984 -), National Crime Victimization Surveys (NCVS). Retrieved from http://hdl.handle.net/1902.5/628506. National Archives and Records Administration [Distributor] V1 [Version].

Farrington, D. P. (1993). Understanding and preventing bullying. In M. Tonry (Ed.), Crime and Justice (Vol. 17, pp. 381-458). Chicago, IL: University of Chicago Press.

Farrell, G., Tseloni, A., \& Pease, K. (2005). Repeat victimization in the ICVS and NCVS. Crime Prevention and Community Safety: An International Journal, 7, 7-18.

Felson, M. (1986). Linking criminal choices, routine activities, informal control, and criminal outcomes. In D. B. Cornish, \& R. V. Clarke (Eds.), The reasoning criminal: Rational choice perspectives on offending (pp. 119-128). New York, NY: Springer-Verlag.

Fitzpatrick, K. M., Dulin, A. J., \& Piko, B. F. (2007). Not just pushing and shoving: Bullying among African American adolescents. Journal of School Health, 77, 16-22.

Gabbidon, S. L. (2009). Race, ethnicity, crime and justice: An international dilemma. Thousand Oaks, CA: SAGE. Gottfredson, M. R. (1981). On the etiology of criminal victimization. Journal of Criminal Law and Criminology, 72, 714-726.

Hazier, R. J., Hoover, J. H., \& Oliver, R. (1991). Student perceptions of victimization by bullies in school. Journal of Humanist Education Development, 29, 143-150. 
Higgins, G. E. (2009). Race, crime and delinquency: A Criminological theory approach. Upper Saddle River, NJ: Prentice Hall.

Hirschi, T. (1969). Causes of delinquency. Berkeley: University of California Press.

Jennings, W. G., Higgins, G. E., Tewksbury, R., Gover, A. R., \& Piquero, A. R. (2010). A longitudinal assessment of the victim-offender overlap. Journal of Interpersonal Violence, 25, 2147-2174.

Jennings, W. G., Piquero, A. R., \& Reingle, J. M. (2011). On the overlap between victimization and offending: A review of the literature. Aggression and Violent Behavior. Retrieved December 18, 2011, from http://www.sciencedirect.com/science/article/pii/S1359178911000954

Lauritsen, J. L., \& Laub, J. H. (2007). Understanding the link between victimization and offending: New reflections on an old idea. Crime Prevention Studies, 22, 55-75.

Lauritsen, J. L., Sampson, R. J., \& Laub, J. H. (1991). The link between offending and victimization among adolescents. Criminology, 29, 265-291.

Lo“sel, F., \& Bliesener, T. (2003). Aggression und delinquenz unter jugendlichen: Untersuchungen von kognitiven und sozialen Bedingunger. Hermann: Luchterhand.

Long, J. S. (1997). Regression models for categorical and limited dependent variables. Thousand Oaks, CA: SAGE. Maccoby, E. E., \& Martin, J. A. (1983). Socialization in the context of the family: Parent-child interaction. In P. Mussen, \& E. M. Heterington (Eds.), Handbook of child psychology: Socialization, personality, and social development (pp. 1-101). New York, NY: Wiley.

Miller, J., \& Decker, S. H. (2001). Young women and gang violence: Gender, street offending, and violent victimization in gangs. Justice Quarterly, 18, 115-140.

Moffitt, T. E. (1993). Adolescence-limited and life-course-persistent antisocial behavior: A developmental taxonomy. Psychological Review, 100, 674-710.

Mustaine, E. E., \& Tewksbury, R. (2000). Comparing the lifestyles of victims, offenders, and victimoffenders: A routine activity theory assessment of similarities and differences for criminal incident participants. Sociological Focus, 33, 339-362.

Nagin, D. S. (2005). Group-based modeling of development over the life course. Cambridge, MA: Harvard University Press.

Osgood, D. W., Wilson, J. K., O'Malley, P. M., Bachman, J. G., \& Johnston, L. D. (1996). Routine activities and individual deviant behavior. American Sociological Review, 61, 635-655.

Olweus, D. (1993). Bullying at school: What we know and what we can do. Oxford, England: Blackwell. Ousey, G. C., Wilcox, P., \& Brummel, S. (2008). Deja vu all over again: Investigating temporal continuity of adolescent victimization. Journal of Quantitative Criminology, 24, 307-355. 
Piquero, A. R. (2008). Taking stock of developemental trajectories of criminal activity over the life course. In A. Liberman (Ed.), The long view of crime: A synthesis of longitudinal research (pp. 23-78). New York, NY: Springer.

Robers, S., Zhang, J., \& Truman, J. (2010). Indicators of School Crime and Safety: 2010 (NCES 2011002/NCJ 230812). Washington, DC: National Center for Education Statistics, U.S. Department of Education, and Bureau of Justice Statistics, Office of Justice Programs, U.S. Department of Justice.

Sampson, R. J., \& Laub, J. H. (1993). Crime in the making: Pathways and turning points Through Life. Cambridge, MA: Harvard University Press.

Sampson, R. J., \& Lauritsen, J. L. (1990). Deviant lifestyles, proximity to crime, and the offender-victim link in personal violence. Journal of Research in Crime and Delinquency, 27, 110-139.

Schreck, C. J., Fisher, B. S., \& Miller, J. M. (2004). The social context of violent victimization: A study of the delinquent peer effect. Justice Quarterly, 21, 23-48.

Schreck, C. J., Stewart, E. A., \& Osgood, D. W. (2008). A reappraisal of the overlap of violent offenders and victims. Criminology, 46, 871-906.

Schreck, C. J., Wirght, R. A., \& Miller, J. M. (2002). A Study of Individual and Situational Antecedents of Violent Victimization. Justice Quarterly, 19, 159-80.

Smith, P. K., \& Sharp, S. (1994). School bullying: Insights and perspectives. London, England: Routledge. Stewart, E. A., Schreck, C. J., \& Simons, R. L. (2006). 'I Ain't Gonna Let No One Disrespect Me': Does the Code of the Street Reduce or Increase Violent Victimization Among African American Adolescents? Journal of Research in Crime and Delinquency, 43, 427-58.

Taylor, T. J., Freng, A., \& Esbensen, F. (2008). Youth gang membership and serious violent victimization: The importance of lifestyles and routine activities. Journal of Interpersonal Violence, 23, 1441-1464.

Taylor, T. J., Peterson, D., \& Esbensen, F. (2007). Gang membership as a risk factor for adolescent violent victimization. Journal of Research in Crime and Delinquency, 44, 351-380.

Thornberry, T. P., \& Krohn, M. D. (2003). Taking stock of delinquency: An overview of the findings from contemporary longitudinal studies. New York, NY: Kluwer Academic/Plenum.

Ttofi, M. M., \& Farrington, D. P. (2008). Bullying: Short-term and long-term effects, and the importance of defiance theory in explanation and prevention. Victims and Offenders, 3, 289-312.

Ttofi,M.M.,\&Farrington, D. P. (2010). School bullying: Risk factors, theories and interventions. In F. Brookman, M. Maguire, H. Pierpoint, \& T. H. Bennett (Eds.), Handbook of crime (pp. 427-457). Cullompton, Devon: Willan.

Walker, S., Spohn, C., \& DeLone, M. (2004). The color of justice: Race and ethnicity in American criminal justice. Belmont, CA: Wadsworth. 